\title{
Ataxia telangiectasia gene mutations in leukaemia and lymphoma
}

\author{
J Boultwood
}

\begin{abstract}
Ataxia telangiectasia (AT) is a rare multisystem, autosomal, recessive disease characterised by neuronal degeneration, genome instability, and an increased risk of cancer. Approximately $10 \%$ of AT homozygotes develop cancer, mostly of the lymphoid system. Lymphoid malignancies in patients with AT are of both $B$ cell and T cell origin, and include Hodgkin's lymphoma, non-Hodgkin's lymphoma, and several forms of leukaemia. The AT locus was mapped to the chromosomal region 11q22-23 using genetic linkage

the normal copy of the ATM gene in some patients with T-PLL, B-CLL, and MCL, establishes somatic inactivation of the ATM gene in the pathogenesis of lymphoid malignancies, and strongly suggests that ATM functions as a tumour suppressor. The presence of missense mutations in the germline of patients with B-CLL has been reported, suggesting that some patients with B-CLL may be constitutional AT heterozygotes. The putative hereditary predisposition of B-CLL, although intriguing, warrants further investigation. (F Clin Pathol 2001;54:512-516)
\end{abstract} analysis in the late 1980 s and the causative gene was identified by positional cloning several years later. The ATM gene encodes a large protein that belongs to a family of kinases possessing a highly conserved C-terminal kinase domain related to the phosphatidylinositol 3-kinase domain. Members of this kinase family have been shown to function in DNA repair and cell cycle checkpoint control following DNA damage. Recent studies indicate that ATM is activated primarily in response to double strand breaks and may be considered a caretaker of the genome. Most mutations in ATM result in truncation and destabilisation of the protein, but certain missense and splicing errors have been shown to produce a less severe phenotype. AT heterozygotes have a slightly increased risk of breast cancer. Atm deficient mice exhibit many of the symptoms found in patients with AT and have a high frequency of thymic lymphoma. The association between mutation of the ATM gene and a high incidence of lymphoid malignancy in patients with AT, together with the development of lymphoma in Atm deficient mice, supports the proposal that inactivation of the ATM gene may be of importance in the pathogenesis of sporadic lymphoid malignancy. Loss of heterozygosity at 11q22-23 (the location of the ATM gene) is a common event in lymphoid malignancy. Frequent inactivating mutations of the ATM gene have been reported in patients with rare sporadic $T$ cell prolymphocytic leukaemia (T-PLL), B cell chronic lymphocytic leukaemia (BCLL), and most recently, mantle cell lymphoma (MCL). In contrast to the ATM mutation pattern in AT, the most frequent nucleotide changes in these sporadic lymphoid malignancies were missense mutations. The presence of inactivating mutations, together with the deletion of
Keywords: lymphoid malignancy; mutation; ataxia telangiectasia gene

Ataxia telangiectasia (AT) is a rare autosomal recessive disease, characterised by cerebella ataxia, immunodeficiency, increased sensitivity to ionising radiation, and a predisposition to malignancies, especially lymphoid neoplasms. ${ }^{12}$ The gene mutated in AT was identified through positional cloning and designated ATM (mutated in AT) in the mid-1990s. ${ }^{34}$ The ATM gene is located at $11 \mathrm{q} 22-23$, spans $184 \mathrm{~kb}$ of genomic DNA, and has 66 exons. ${ }^{47}$ The ATM gene encodes a nuclear phosphoprotein of approximately $350 \mathrm{kDa}$ (3056 amino acids) and is ubiquitously expressed. ${ }^{89}$ The protein is a member of a novel family of large proteins, which show sequence homology to the catalytic domain of phosphatidylinositol 3 kinase, ${ }^{3}$ and are implicated in cell cycle regulation, signal transduction, and the response to DNA damage. ${ }^{410}$ There is evidence to suggest that these proteins respond to DNA damage by phosphorylating one or more substrates, including $\mathrm{p} 53$, c-Abl, and replication protein A (RPA), to recruit proteins to regions of DNA repair and/or to activate radiation signal transduction pathways. ${ }^{11-14}$ The kinase activity of ATM rises as a response to ionising radiation and recent studies suggest that ATM is activated in response to double strand breaks, one of the major consequences of this form of radiation. ${ }^{12}{ }^{13}$ It is now known that ATM is required for cell cycle checkpoint control at the G1/S border, S phase, and G2/M checkpoints after DNA strand breakpoint damage. ${ }^{14} 15$ Consistent with these observation, it has been shown that cells derived from patients with AT are hypersensitive to DNA damaging agents such as ionising radiation and restriction enzymes that produce double stranded DNA breaks. ${ }^{16}$ It is becoming increasingly clear that ATM is a key player in DNA damage recognition and in activating cell cycle 
checkpoints to reduce the progress of cells harbouring damaged DNA through the cell cycle. Like p53, the guardian of the genome, ATM is fundamental to genomic stability.

\section{The ATM gene and AT}

To date, more than 100 mutations have been identified among patients with AT, and these occur over the entire coding region of the ATM gene. ${ }^{18-21}$ Most mutations (70-80\%) are predicted to produce either a truncated protein product or no product at all. ${ }^{18} 2122$ Inactivation of the ATM gene is caused primarily by small deletions or insertions. Missense mutations have been described but they do not seem to be common in $\mathrm{AT}^{20}{ }^{21}$ Individuals heterozygous for mutations have an increased risk of cancer, particularly breast cancer. ${ }^{23-25}$ Patients with homozygous ATM mutations are predisposed to cancer, with a proportion of patients developing multiple neoplasms. ${ }^{12}{ }^{24}$ The cancers found most frequently are malignancies of the lymphoid system. ${ }^{2}$ A 250 fold and 750 fold increase in the risk of lymphoma has been determined for white and African-American patients with AT, respectively, compared with the normal population. ${ }^{26}$ The increase in lymphoid malignancy includes both $\mathrm{T}$ and $\mathrm{B}$ cell tumours. ${ }^{2} \mathrm{~B}$ cell non-Hodgkin's lymphoma (B-NHL) is the most frequent B cell malignancy in patients with $\mathrm{AT}^{2}$ The pronounced predisposition of patients with AT to develop neoplasms of the $T$ cell lineage is well recognised and can occur at any age. ${ }^{12}{ }^{24}$ It has been estimated that $\mathrm{T}$ cell tumours occur approximately four to five times more frequently than B cell tumours, and comprise $\mathrm{T}$ acute lymphocytic leukaemia (T-ALL), T cell lymphoma, or $\mathrm{T}$ prolymphocytic leukaemia (T-PLL). ${ }^{2}$

\section{Lymphoid defects and malignancy in the AT mouse model}

Several mouse models for AT have been generated using gene targeting. These murine models have lost functional Atm protein. ${ }^{27-29}$ Atm deficient mice (Atm-/- mice) have characteristics that are similar in many respects to those of human AT and these AT mouse models confirm that the correct gene had been cloned. ${ }^{27-29}$ Atm deficient mice are immunodeficient, display severe defects in T cell maturation, and show a high incidence of thymomas or thymic lymphoblastic lymphomas. ${ }^{27-29}$ Primary cells derived from the Atm-/- mice also show cell cycle checkpoint defects in common with AT, including hypersensitivity to $\gamma$ irradiation and defective cell cycle checkpoint control after $\gamma$ irradiation. ${ }^{1415} 27$

The AT related immune defects in Atm-/mice comprise thymus hypoplasia defective lymphoid differentiation, and impaired $\mathrm{T}$ dependent immune responses. ${ }^{27-29}$ Several groups have established that ATM mice develop thymic lymphomas by the age of 4 months. ${ }^{27-29}$ Multiple chromosomal abnormalities involving the $\mathrm{T}$ cell receptor $\beta$ locus have also been reported in the monoclonal cells derived from Atm-/- mice. ${ }^{29}$ Thus, as for lymphoid tumorigenesis in patients with AT, genetic instability seems to be a key feature in the early onset of the lymphoid tumours in Atm-/- mice.

The study of Atm-/- mice has been of value in the elucidation of the pathogenesis of lymphoid tumorigenesis in AT. Of particular interest are the recent data suggesting that Atm is involved in the regulation of $\mathrm{V}(\mathrm{D}) \mathrm{J}$ recombination, and that impairment in this process could contribute to genetic instability and tumorigenesis in ATM-/- lymphocytes. ${ }^{30}$ This proposal is supported by the observation that the onset of thymic lymphoma is greatly suppressed in Atm-/- and RAG2-/- double null mice, which are totally deficiency in $\mathrm{V}(\mathrm{D}) \mathrm{J}$ recombination. ${ }^{30}$

\section{The ATM gene in human lymphoid malignancies}

The ATM gene is assigned to $11 \mathrm{q} 22.3 .{ }^{5}$ Chromosome loss at $11 \mathrm{q} 22-23$ is a frequent event in a range of sporadic malignancies, supporting a role for the ATM gene in tumorigenesis. It is of interest to haematopathologists that deletion of the long arm of chromosome $11(\operatorname{del}(11 \mathrm{q}))$ is one of the most common chromosomal aberrations observed in lymphoid neoplasms. ${ }^{31}{ }^{32}$ For example, it has been estimated by Johansson et al that $16 \%$ of patients with non-Hodgkin's (NHL) show deletions of $11 \mathrm{q} 22-23,{ }^{31}$ and a similar incidence has been reported in B cell chronic lymphocytic leukaemia (B-CLL). ${ }^{33}$ The association between mutation of the ATM gene and a high incidence of lymphoid neoplasia in patients with AT, together with the development of lymphoma in Atm deficient mice, supports the hypothesis that inactivation of the ATM gene might be of importance in the pathogenesis of lymphoid neoplasms. The frequency of del(11q) in lymphoid malignancy adds further weight to this proposal.

THE ATM GENE IN HUMAN LEUKAEMIA

Complete or partial loss of the long arm of chromosome 11 is one of the most common karyotypic abnormalities seen in sporadic T-PLL, ${ }^{34}$ a rare aggressive mature $\mathrm{T}$ cell leukaemia, with similarities to the mature $\mathrm{T}$ cell leukaemia seen in patients with $\mathrm{AT}^{35}$ Indeed, the critical region of chromosome 11q in T-PLL has been mapped to 11q22.3, and includes the ATM locus. ${ }^{34}$ In 1997, loss of function mutations in the remaining allele of the ATM gene were demonstrated in six of six cases of T-PLL with loss of one allele of the ATM gene. ${ }^{36}$ Thus, both ATM alleles can be disrupted by deletion and/or point mutation in T-PLL suggesting, for the first time, that ATM functions as a tumour suppressor gene in tumours of individuals without AT. ${ }^{36}$ Similarly, Vorechovsky et al reported inactivating mutations of the ATM gene in 17 of 37 patients with T-PLL. The ATM mutations seen in T-PLL were primarily missense mutations occurring in the region corresponding to the kinase domain, which is highly conserved among ATM related proteins and is believed to be involved in cell cycle regulation and in the response to DNA damage. ${ }^{10}{ }^{34}$ Although very different to the ATM mutation pattern seen in 
AT, the missense mutations observed in T-PLL were still thought to be inactivating because of the change of conserved residues in the active site of the ATM kinase. ${ }^{37} 38$ The mutations described are predicted to interfere with the catalytic function of ATM or directly prevent ATP binding or substrate recognition. ${ }^{37}$ It has been suggested that the frequency of ATM mutation in T-PLL (around 50\%) may in fact be underestimated as a result of the inefficiency of mutation detection for this large gene. ${ }^{38}$ It is interesting to note that ATM is usually structurally rearranged in T-PLL. ${ }^{39}$

Intriguingly, Vorechovsky et al raised the possibility of a putative increase of AT heterozygotes in patients with T-PLL, but because constitutional DNA was not available for analysis, a hereditary predisposition to T-PLL could not be investigated. ${ }^{37}$ The acquired character of ATM mutations has been demonstrated in three patients with T-PLL in one other study. ${ }^{34}$ The predominance of truncating mutations in most AT affected families does suggest, however, that patients with cancer and ATM missense mutations are not AT heterozygotes. ${ }^{38}$ Large data sets and prospective studies will be needed to establish that constitutional AT heterozygosity is associated with a risk of T-PLL.

Patients with AT frequently develop $\mathrm{T}$ lineage $\mathrm{ALL}^{2}$ and most Atm-/- mice develop $\mathrm{T}$ cell lymphomas. ${ }^{27}$ These data suggest that the ATM gene might play a role in the malignant transformation of $\mathrm{T}$ cells. The importance of inactivation of the ATM gene in T-PLL is now clear. ${ }^{34}{ }^{36}$ How frequently inactivation of this gene occurs in other $\mathrm{T}$ cell malignancies requires further investigation. Children with AT often develop $\mathrm{T}$ lineage ALL. ${ }^{2}$ However, Takeuchi et al failed to demonstrate the presence of inactivating mutations in 18 patients with childhood T-ALL, although three of these cases showed loss of heterozygosity at the ATM locus. ${ }^{40}$

$\mathrm{B}-\mathrm{CLL}$ is one of the most common forms of adult leukaemia and is characterised by the accumulation of mature $\mathrm{CD} 5+\mathrm{B}$ cells. ${ }^{41}$ Approximately $14 \%$ of patients with B-CLL show deletion of $11 \mathrm{q} 22-23$, and it is associated with extensive lymph node involvement and poor survival..$^{33}$ Recent data have shown inactivation of the ATM gene in B-CLL. ${ }^{43}$ Mutation of the ATM gene was reported in six of the 32 patients examined and comprised point mutations, deletion, and insertions and occurred over the entire coding region of the ATM gene. ${ }^{43}$ Total or partial inactivation of ATM protein expression was seen in eight of the 20 B-CLL tumours examined. Similarly, others have also shown that ATM mutations occur in a proportion of patients with B-CLL. ${ }^{44}$ The role of the ATM gene in the molecular pathogenesis of B-CLL is not known. However, the ATM protein mediates the p53 response during cell apoptosis, and it is tempting to speculate that loss of the ATM protein may result in B-CLL resistance to apoptosis, ${ }^{43}$ a characteristic feature of this form of leukaemia. ${ }^{41}$
It has long been recognised that there is a familial aspect to susceptibility to B-CLL, and it has been suggested that ATM carrier status is a predisposing factor. ${ }^{43}$ In support of this proposal, two independent studies have each reported two missense mutations in the germline of patients with B-CLL, supporting the increased prevalence of germline carriers of mutated ATM alleles among patients with B-CLL. ${ }^{43}$ However, others have suggested that at least some of these changes may simply reflect rare variants in ATM rather than genuine cancer predisposing mutations. ${ }^{45}$ The existence of two distinct AT carrier populations; one group with a truncating allele together with a normal allele, and a second group with a missense mutation coupled with a normal allele, with the latter group at greater risk for tumorigenesis, has been recently hypothesised. ${ }^{46}{ }^{47}$

THE ATM GENE IN HUMAN LYMPHOMA

Further support for the proposal that inactivation of the ATM gene may be of importance to the pathogenesis of a wide range of human lymphoid malignancies came very recently, with several groups showing inactivation of the ATM gene in the mature, virgin B cell neoplasm, mantle cell lymphoma (MCL). ${ }^{48} 49$ MCL usually presents as advanced stage disease and is characterised genetically by the $\mathrm{t}(11 ; 14)$ (q13; q32) translocation and overexpression of the cyclin D1 gene. ${ }^{50}$ In common with T-PLL and B-CLL, del(11q) is also reported frequently in MCL, and the ATM gene maps to the deleted segment in this malignancy. ${ }^{49} 51$ Schaffner et al performed mutation analysis on the ATM gene in 12 sporadic cases of MCL; all seven cases with a deletion of one ATM allele showed mutation of the remaining ATM allele, resulting in aberrant transcript splicing, truncation, or alteration of the protein. ${ }^{48}$ In addition, in two cases without del(11q), biallelic ATM mutations were found. ${ }^{48}$ In those cases investigated, the ATM mutations were shown to be somatic rather than germline in origin. ${ }^{48}$ The inactivation of both alleles of the ATM gene in a high proportion of patients with MCL supports the proposal that ATM functions as a tumour suppressor in MCL and plays an important role in the pathogenesis of this malignancy. ${ }^{48}$

How relevant inactivation of the ATM gene is to the pathogenesis of other forms of lymphoma requires further analysis. AT homozygotes show an increased risk of developing B cell malignancies, particularly B-NHL. ${ }^{2}$ However, missense mutations in the ATM gene were reported in tumour DNA from only a small proportion of patients with B-NHL or B-NHL cell lines (three of 37) in one earlier investigation. ${ }^{37}$ More recently, a large study to investigate the clinicobiological importance of acquired del(11q) involving loss of one ATM allele in B-NHL has been performed. ${ }^{52}$ One hundred and thirty five patients with B-NHL were studied and a highly significant association was found between deletion of one ATM allele and shorter survival $(\mathrm{p}<0.0001)$. It has been suggested that, although possibly not a primary genetic lesion in most cases of 
B-NHL, the deletion of ATM may be a major cytogenetic determinant of outcome. ${ }^{52}$

\section{Future directions}

Inactivation of the ATM gene clearly plays an important role in the pathogenesis of some sporadic lymphoid malignancies including T-PLL, B-CLL, and MCL. The identification of inactivating mutations of the ATM gene in these lymphoid malignancies furthers our understanding of the molecular pathology of these disorders and offers some hope for future management using genetic based treatments. In particular, the use of ATM antisense technology to combat various lymphoid malignancies is an exciting possibility. What is less clear is the frequency of inactivating mutations of ATM in other forms of lymphoid malignancy, both leukaemias and lymphomas. The strong association between inactivating mutations of the ATM gene and the presence of $\operatorname{del}(11 \mathrm{q})$ in B-CLL, T-PLL, and MCL indicates that other lymphoid malignancies possessing $\operatorname{del}(11 \mathrm{q})$ are a priority for ATM mutation screening. The degree to which the risk of cancer is increased in AT heterozygotes also require further study. The determination of the frequency of ATM missense mutations in the general population is the subject of intensive investigation and should shed some light on this important question.

Studies in Atm-/- mice have provided evidence suggesting that ATM plays a role in the regulation of $\mathrm{V}(\mathrm{D}) \mathrm{J}$ recombination, and impairment of this process could contribute to genetic instability and tumorigenesis in ATM-/- lymphocytes. It will be necessary to elucidate the precise mechanism of these potential functions of ATM to understand AT lymphoid tumorigenesis fully.

1 Shiloh Y. Ataxia-telangiectasia: closer to unraveling the mystery. Eur f Hum Genet 1995;3:116-38.

Taylor AM, Metcalfe JA, Thick M, et al Leukaemia and lymphoma in ataxia telangiectasia. Blood 1996;87:423-38.

3 Savitsky K, Bar-Shira A, Gilad S, et al. A single ataxia telangiectasia gene with a product similar to PI-3 kinase. telangiectasia gene with a
Science $1995 ; 268: 1749-53$.

4 Savitsky K, Sfez S, Tagle DA, et al. The complete sequence of the coding region of the ATM gene reveals similarity to cell cycle regulators in different species. Hum Mol Gene 1995; 4:2025-32.

5 Gattie RA, Berkel I, Boder E, et al. Localization of an ataxiatelangiectasia gene to chromosome 11q22-23. Nature 1988;336:577-80.

6 Uziel T, Savitsky K, Platzer M, et al. Genomic organization of the ATM gene. Genomics 1996;33:317-20.

7 Rasio D, Negrini M, Croce CM, et al. Genomic organization of the ATM locus involved in ataxia-telangiectasia. Cancer Res 1995;55:6053-7.

8 Brown KD, Ziv Y, Sadanandan SN, et al. The ataxiatelangiectasia gene product, a constitutively expressed nuclear protein that is not up-regulated following genome nuclear protein that is not up-regulated following gen
damage. Proc Natl Acad Sci U S A 1997;94:1840-5.

9 Watters D, Khanna KK, Beamish $\mathrm{H}$, et al. Cellular localisation of the ataxia-telangiectasia (ATM) gene product and discrimination between mutated and normal forms. discrimination between mut
Oncogene 1997;14:1911-21.

10 Zakian VA. ATM-related genes: what do they tell us about functions of the human gene? Cell 1995;82:685-7.

11 Lavin MF, Khanna KK. ATM: the protein encoded by the gene mutated in the radiosensitive syndrome ataxiatelangiectasia. Int F Radiat Biol 1997;75:101-14.

12 Banin S, Moyal, L, Shieh S, et al. Enhanced phosphorylation of $\mathrm{p} 53$ by ATM in response to DNA damage. Science 1998;281:1674-7.

13 Canman CE, Lim DS, Cimprich KA, et al. Activation of the ATM kinase by ionizing radiation and phosphorylation of p53. Science 1998;281:1677-9.

14 Baskaran R, Wood LD, Whitaker LL, et al. Ataxia telangiectasia mutant protein activates c-Abl tyrosine
kinase in response to ionizing radiation. Nature 1997;387: kinase in
$15 \mathrm{Xu} \mathrm{Y}$, Baltimore D. Dual roles of ATM in the cellular response to radiation and in cell growth control. Genes Dev 1996;10:2401-10.

16 Levis WR, Dattner AM, Shaw JS. Selective defects in T cell function in ataxia-telangiectasia. Clin Exp Immunol 1979; 37:44-9.

17 Metcalfe JA, Parkhill, J, Campbell L, et al. Accelerated telomere shortening in ataxia telangiectasia. Nat Genet 1996;13:350-3.

18 Concannon P, Gattie RA. Diversity of ATM gene mutations detected in patients with ataxia-telangiectasia. Hum Mutat 1997;10:100-7.

19 Wright J, Teraoka S, Onengut S, et al. A high frequency of distinct ATM mutations in ataxia-telangiectasia. Am f Hum Genet 1996;59:839-46.

20 Gilad S, Khorsavi R, Shkedy D, et al. Predominance of null mutations in ataxia-telangiectasia. Hum Mol Genet 1996;5: 433-9.

21 Stankovic T, Kidd AMJ, Sutcliffe A, et al. ATM mutations and phenotypes in ataxia-telangiectasia families in the British Isles: expression of mutant ATM and the risk of leukaemia, lymphoma and breast cancer. Am f Hum Genet 1998; 62:334-45.

22 Telatar M, Wang S, Castellvi-Bel S, et al. A model for ATM heterozygote identification in a large population: four founder-effect ATM mutations identify most Costa Rican patients with ataxia telangiectasia. Mol Genet Metab 1998;64:36-43.

23 Swift M, Reitnauer PJ, Morrell D, et al. Breast and other cancers in families with ataxia-telangiectasia. $N$ Engl f Med 1987;316:1289-94.

24 Swift M, Morrell D, Massey RB, et al. Incidence of cancer in 161 families affected by ataxia-telangiectasia. $N$ Engl f Med 1991;325:1831-6.

25 Athma P, Rappaprot R, Swift M. Molecular genotyping shows that ataxia-telangiectasia heterozygotes are predisposed to breast cancer. Cancer Genet Cytogenet 1996;92: $130-4$.

26 Morrell D, Cromartie E, Swift M. Mortality and cancer incidence in 263 patients with ataxia-telangiectasia. $7 \mathrm{Natl}$ Cancer Inst 1986;77:89-92.

27 Barlow C, Hirotsune S, Paylor R, et al. Atm-deficient mice: a paradigm of ataxia telangiectasia. Cell 1996;86:159-71.

28 Elson A, Wang Y, Daugherty C, et al. Pleiotropic defects in ataxia-telangiectasia protein-deficient mice. Proc Natl Acad Sci U S A 1996;93:13084-9.

$29 \mathrm{Xu}$ Y, Ashley T, Brainerd EE, et al. Targeted disruption of ATM leads to growth retardation, chromosomal fragmentation during meiosis, immune defects, and thymic lymphoma. Genes Dev 1996;10:2411-22.

30 Liao MJ, Van Dyke T. Critical role for Atm in suppressing V(D)J recombination-driven thymic lymphoma. Genes Dev 1999;13:1246-50.

31 Johansson B, Mertens F, Mitelman F. Cytogenetic deletion maps of hematologic neoplasms: circumstantial evidence for tumour suppressor loci. Genes Chromosomes Cancer 1993;8:205-18.

32 Stilgenbauer S, Liebisch P, James MR, et al. Molecular cytogenetic delineation of a novel critical genomic region in chromosome bands 11q22.3-23.1 in lymphoproliferative disorders. Proc Natl Acad Sci U S A 1996;93:11837-41.

33 Fegan C, Robinson H, Thompson P, et al. Karyotypic evolution in CLL: identification of a new sub-group of patients with deletions of $11 \mathrm{q}$ and advanced or progressive disease. Leukemia 1995;93:11837-41.

34 Stoppa-Lyonnet D, Soulier J, Lauge A, et al. Inactivation of the ATM gene in T-cell prolymphocytic leukemias. Blood 1998;91:3920-6.

35 Matutes E, Brito-Bapapulle V, Swansbury J, et al. Clinical and laboratory features of 78 cases of T-prolymphocytic leukemia. Blood 1991;78:3269-74.

36 Stilgenbauer S, Schaffner, C, Litterst A, et al. Biallelic mutations in the ATM gene in T-prolymphocytic leukaemia. Nat Med 1997;3:1155-9.

37 Vorechovsky I, Luo L, Dyer MJS, et al. Clustering of missense mutations in the ataxia-telangiectasia gene in sporadic T-cell leukaemia. Nat Genet 1997;17:96-9.

38 Uhrhammer N, Bay J-O, Bignon, YJ. Seventh international workshop on ataxia-telangiectasia. Cancer Res 1998;58 3480-5.

39 Yuille MA, Coignet LJ, Abraham SM, et al. ATM is usually rearranged in T-cell prolymphocytic leukaemia. Oncogene 1998;16:789-96.

40 Takeuchi S, Koike M, Park S, et al. The ATM gene and susceptibility to childhood T-cell acute lymphoblastic leukaemia. Br f Haematol 1998;103:536-8.

41 Rozman C, Monserrat E. Chronic lymphocytic leukaemia. N Engl f Med 1995;333:1052-9.

42 Neilson AR, Auer R, White, et al. Deletions at $11 \mathrm{q}$ identify a subset of patients with typical CLL who show consistent disease progression and reduced survival. Leukemia 1997; 1:1929-32.

43 Stankovic T, Weber P, Stewart G, et al. Inactivation of ataxia telangiectasia mutated gene in B-cell chronic lymphocytic leukaemia. Lancet 1999;353:26-9.

44 Bullrich F, Rasio D, Kitada S, et al. ATM mutations in B-cell chronic lymphocytic leukaemia. Cancer Res 1999;59: 24-7.

45 Vorechovsky I, Ortmann E, Steinmann D, et al. Missense mutations at the ATM gene and cancer risk. Lancet 1999;353:1276. 
46 Gatti RA, Tward A, Concannon P, et al. Cancer risk in ATM heterozygotes: a model of phenotypic and mechanistic differences between missense and truncating mutations. Mol Genet Metab 1999;68:419-23.

47 Meyn MS. Ataxia-telangiectasia, cancer and the pathobiology of the ATM gene. Clin Genet 1999;55:289-304.

48 Schaffner C, Idler I, Stilgenbauer S, et al. Mantle cel lymphoma is characterized by inactivation of the ATM gene. Proc Natl Acad Sci U S A 2000;97:2773-8.

49 Stilgenbauer S, Schaffner C, Winkler D, et al. The ATM gene in the pathogenesis of mantle-cell lymphoma. Ann Oncol 2000;11:127-30.
50 Samaha H, Dumontet C, Ketterer N, et al. Mantle cell lymphoma: a retrospective study of 121 cases. Leukemia 1998;12:1281-7.

51 Stilgenbauer S, Winkler D, Ott G, et al. Molecular characterization of $11 \mathrm{q}$ deletions points to a pathogenic role of the ATM gene in mantle cell lymphoma. Blood 1999;94:3262-4.

52 Cuneo A, Bigoni R, Rigolin GM, et al. Acquired chromosome $11 \mathrm{q}$ deletion involving the ataxia telangiectasia locus in B-cell non-Hodgkin's lymphoma: correlation with clinicobiologic features. F Clin Oncol 2000;18:260714 .

\title{
Narrative Based Medicine, An Interdisciplinary Conference
}

\author{
Research, Narrative, and Practice
}

A two day conference-Monday 3rd and Tuesday 4th September 2001

$$
\text { Homerton College, Cambridge, UK }
$$

BMF Publishing Group

For full details contact: BMA/BMJ Conference Unit, Tavistock Square, London, WC1H 9JP Tel: +44 (0)20 7383 6819; fax: +44 (0)207383 6663; email: clyders@bma.org.uk.

www.quality.bmjpg.com

\section{1st Asia Pacific Forum on Quality Improvement in Health Care}

\author{
Three day conference
}

\section{Wednesday 19 to Friday 21 September 2001 \\ Sydney, Australia}

We are delighted to announce this forthcoming conference in Sydney. Authors are invited to submit papers (call for papers closes on Friday 6 April), and delegate enquiries are welcome.

The themes of the Forum are:

- Improving patient safety

- Leadership for improvement

- Consumers driving change

- Building capacity for change: measurement, education and human resources

- The context: incentives and barriers for change

- Improving health systems

- The evidence and scientific basis for quality improvement.

Presented to you by the BMJ Publishing Group (London, UK) and Institute for Healthcare Improvement (Boston, USA), with the support of the the Commonwealth Department of Health and Aged Care (Australia), Safety and Quality Council (Australia), NSW Health (Australia), and Ministry of Health (New Zealand).

For more information contact: quality@bma.org.uk or fax +44(0)20 73836869 